\title{
REMOVAL OF METHYLENE BLUE FROM AQUEOUS SOLUTION BY BIOADSORPTION ONTO Ricinus communis EPICARP ACTIVATED CARBON
}

\author{
T. Santhi ${ }^{* 1}$, S. Manonmani ${ }^{2}$ \\ ${ }^{1}$ Department of Chemistry, Karpagam University, Coimbatore-641021, India \\ ${ }^{2}$ Department of Chemistry, PSG College of Arts and Science, Coimbatore-641014, India
}

Received 19 May 2009; received in revised form 22 July 2009

\begin{abstract}
Carbon prepared from the epicarp of Ricinus communis was used to remove a textile dye (methylene blue (MB)) from an aqueous solution by adsorption technique under varying conditions of agitation time, dye concentration, adsorbent dose and $\mathrm{pH}$. Adsorption depended on solution $\mathrm{pH}$, dye concentration, carbon concentration and contact time. Adsorption followed both Langmuir and Freundlich isotherm models. The adsorption capacity was found to be $62.5 \mathrm{mg} / \mathrm{g}$ at a neutral $\mathrm{pH}$ of 7 for the adsorbent size of $125-250 \mu \mathrm{m}$ at room temperature $\left(32 \pm 2^{\circ} \mathrm{C}\right)$. The kinetics of adsorption of MB obeys Pseudo-first order. The results in this study indicated that activated carbon from Ricinus communis was an attractive candidate for removing cationic dyes from the dye wastewater.
\end{abstract}

Keywords: Epicarp, Ricinus communis, Adsorption, Methylene blue, Kinetics

DOI:10.3329/cerb.v13i1.2518

\section{Introduction}

Dyes have long been used in dyeing, paper and pulp, textiles, plastics, leather, cosmetics and food industries[1]. Colour stuff discharged from these industries poses certain hazards and environmental problems. These coloured compounds are not only aesthetically displeasing but also inhibiting sunlight penetration into the water and affecting aquatic ecosystem [2]. Dyes usually have complex aromatic molecular structures which make them more stable and difficult to biodegrade. Furthermore, many dyes are toxic to some microorganisms and may cause direct destruction or inhibition of their catalytic capabilities [3].

There are various conventional methods of removing dyes from aqueous solutions. Among these methods, adsorption is by far the most versatile and widely used method because of its low cost and ease of operation. A number of agricultural waste and by-products of cellulosic origin have been studied for their capacity to remove dyes from aqueous solutions, such as peanut hulls [4], maize bran [5], sawdust [6], sugar beet pulp [7], crab shell [8], cornstarch [9], rice husk [10], chitin [11], orange waste [12], lemon peel [13], granular kohlrabi peel [14],raw barley straw [15] and eggshell [16].

Therefore, there is the need to look for low cost alternatives in easily available bio-materials, which can adsorb dyes from wastewaters. In this paper, we attempt to use activated carbon developed from Ricinus

${ }^{*}$ Corresponding author Email: ssnilasri@yahoo.co.in communis, as an adsorbent for the removal of dyes from water. Annual production of Ricinus communis is estimated to be more than 1.0 tons globally, of which India accounts for $60 \%$ of the production. The epicarp of Ricinus is a segregated waste by-product (35\% of production) during segregation of Ricinus Communis seed. Since the epicarp of Ricinus is available free of cost, only the carbonization of its involved for the wastewater treatment. Therefore the main objective of this study was to evaluate the possibility of using dried epicarp of Ricinus to develop a new low-cost activated carbon and study its application to remove methylene blue from simulated wastewater. The various parameters such as $\mathrm{pH}$, adsorbent dose, initial dye concentration, adsorbent particle size were investigated.

\section{Experimental}

\subsection{Preparation of the epicarp of Ricinus communis adsorbent}

The epicarp of Ricinus communis was obtained from an agricultural farm in Coimbatore District, Tamil Nadu, India. It was air-dried and powdered in a grinder. The powder was then soaked in concentrated $\mathrm{H}_{2} \mathrm{SO}_{4}$ for 12 hours and washed thoroughly with distilled water till it attained neutral $\mathrm{pH}$ and then soaked in two percent $\mathrm{NaHCO}_{3}$ overnight in order to remove any excess acid present. Then the material was washed again with distilled water and dried at $110 \pm 2^{\circ} \mathrm{C}$. The dry biomass was crushed into granules, sieved to different particle sizes, and then preserved in a desiccator for use.

(C)Bangladesh Uni. of Engg. E Tech. 


\subsection{Preparation of cationic dye solutions}

Methylene blue in commercial purity obtained from Fluka was used without further purification. A stock solution of $1000 \mathrm{mg} / \mathrm{L}$ of the MB dye was prepared by dissolving $1 \mathrm{~g}$ of the dye in 1 liter double distilled water. The experimental solutions were obtained by diluting the dye stock solutions in accurate proportions to different initial concentrations.

\subsection{Experimental methods and measurements}

Bioadsorption experiments were carried out in a rotary shaker at $150 \mathrm{rpm}$ using $250 \mathrm{~mL}$-shaking flasks containing $50 \mathrm{~mL}$ of dye solutions at different concentrations and initial $\mathrm{pH}$ values. The initial $\mathrm{pH}$ values of the solutions were previously adjusted with 0.1 $\mathrm{M} \mathrm{HCl}$ or $\mathrm{NaOH}$ using a DEEP VERSION model (EI) $\mathrm{pH}$ meter. The adsorbent $(0.1 \mathrm{~g})$ was added to each flask, and then the flasks were sealed to prevent any change in volume during the experiments. After shaking the flasks for a predetermined time interval, the samples were withdrawn from the flasks and the dye solutions were separated from the adsorbent by filtration after centrifugation. The $\mathrm{pH}$ values of the separated dye solutions were again measured for estimating their change. Dye concentrations in the supernatant solutions were estimated by measuring absorbance at maximum wavelengths of dye with a Systronics Spectrophotometer-104. The experiment was carried out at $480 \mathrm{~nm}$; throughout the experiment the wavelength was constant.

The amount of dye adsorbed by the biomass was calculated using the following equation:

$$
q=C_{0}-C_{e} V / W
$$

Where $q(\mathrm{mg} / \mathrm{g})$ is the amount of dye adsorbed by the biomass, $C_{0}$ and $C_{e}(\mathrm{mg} / \mathrm{L})$ are the initial and equilibrium liquid phase concentration of dye. $V(\mathrm{~L})$ the initial volume of dye solution, and $W(\mathrm{~g})$ the weight of the biomass. All the experiments are duplicated and only the mean values are reported. The maximum deviation observed was less than $2 \%$.

Influence of each parameter $(\mathrm{pH}$, initial dye concentration, adsorbent particle size and carbon concentration) were evaluated in an experiment by varying the parameter under evaluation, while all other parameters in the experiment were maintained as constant. The experiments were conducted with duplicate and the negative controls (with no adsorbent) to ensure that adsorption was by the epicarp of Ricinus Commnis biomass and not by the container. The surface morphology of activated carbon (activated carbon from Ricinus communis) was visualized via scanning electron microscopy(SEM).

\section{Results and Discussion}

\subsection{Influence of initial $p H$}

The effect of initial $\mathrm{pH}$ on bioadsorption percentage of dye was examined over a range of $\mathrm{pH}$ values from 2 to 10 and the results are presented in Figure 1. As elucidated in Figure 1, the dye removal was minimum at the initial $\mathrm{pH} 2$. The dye adsorbed increased as the $\mathrm{pH}$ was increased from $\mathrm{pH} 2$ to 7 . Incremental dye removal was not significant beyond $\mathrm{pH} 7$. For this reason, $\mathrm{pH} 7$ was selected for future experiments.

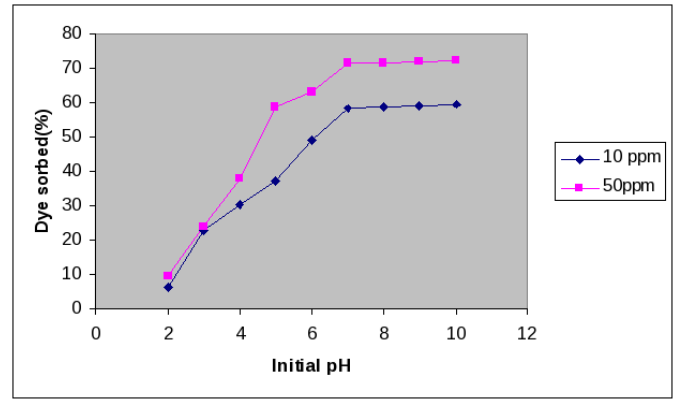

Figure 1: Influence of initial $\mathrm{pH}$ on bioadsorption of $\mathrm{MB}$ by carbon of the epicarp of Ricinus communis (adsorbent dose: $100 \mathrm{mg} / 50 \mathrm{~mL}$; particle size: $125-250 \mu \mathrm{m}$; contact time: $2 \mathrm{~h}$ )

After adsorption experiments, it was found that at low $\mathrm{pH}$, the dyes become protonated, the electrostatic repulsion between the protonated dyes and positively charged adsorbent sites results in decreased adsorption. Higher adsorption at increased $\mathrm{pH}$ may be due to increased protonation by the neutralization of the negative charges at the surface of the adsorbent; which facilitates the diffusion process and provides more active sites for the adsorbent.

\subsection{Influence of initial dye concentration}

The influence of dye concentration on bioadsorption of dye is shown in Figure 2. When the dye concentration was increased from 10 to $50 \mathrm{mg} / \mathrm{L}$, the percentage of dye adsorbed increased from $75.2 \%$ to $91.2 \%$.

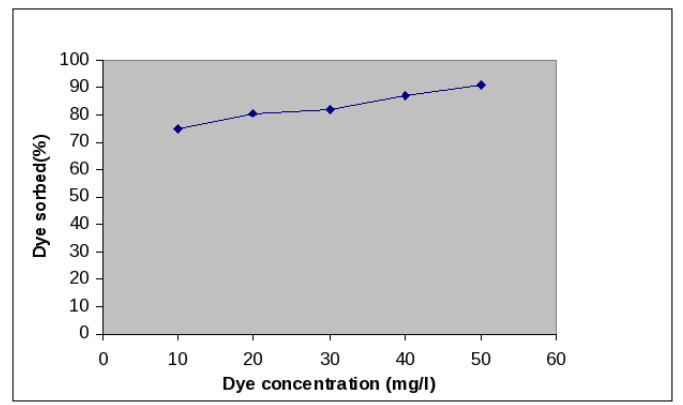

Figure 2: Influence of dye concentration on bioadsorption of MB by carbon of the epicarp of Ricinus communis (adsorbent dose: $100 \mathrm{mg} / 50 \mathrm{~mL}$; particle size: $125-250 \mu \mathrm{m}$; contact time: $3 \mathrm{~h}$; $\mathrm{pH}$ : 7.0) 


\subsection{Adsorption Isotherm}

The Langmuir and Freundlich equation were employed to study the adsorption isotherms of dye.

The linearised form of the Langmuir equation [17] is as follows

$$
C_{e} / q_{e}=1 /\left(a Q_{m}\right)+C_{e} / Q_{m}
$$

where $C_{e}(\mathrm{mg} / \mathrm{L})$ is the concentration of the dye solution at equilibrium, $q_{e}(\mathrm{mg} / \mathrm{g})$ is the amount of dye sorbed at equilibrium, $Q_{m}$ is the maximum adsorption capacity and represents a practical limiting adsorption capacity when the adsorbent surface is fully covered with monolayer adsorbent molecule and $a$ is Langmuir constant. The $Q_{m}$ and $a$ values are calculated from the slopes $\left(1 / Q_{m}\right)$ and intercepts $\left(1 / a Q_{m}\right)$ of linear plots of $C_{e} / q_{e}$ versus $C_{e}$.

The linearised form of the Freundlich equation [18] is as follows:

$$
\ln Q_{e}=\ln K+(1 / n) \ln C_{e}
$$

where $Q_{e}$ is the amount of dye adsorbed at equilibrium, $C_{e}$ is the concentration of the dye solution at equilibrium and $1 / n$ is empirical constant and indicate adsorption capacity and intensity, respectively. Their values were obtained from the intercepts $(\ln K)$ and slope $(1 / n)$ of linear plots of $\ln Q_{e}$ versus $\ln C_{e}$.

The $Q_{m}$ and $a$ values in the Langmuir equation, the $K$ and $1 / n$ values in the Freundlich equation are given in the Table 1. From the results in Table 1, it could be concluded that the adsorption of MB followed the Langmuir and Freundlich model.

Table 1: The $Q_{m}, a$ values in the Langmuir equation, the $K$ and $1 / n$ values in Freundlich equation

\begin{tabular}{cc|cc}
\hline \multicolumn{2}{c|}{ Langmuir } & \multicolumn{2}{c}{ Freundlich } \\
\hline$Q_{m}(\mathrm{mg} / \mathrm{g})$ & $a$ & $K$ & $1 / n$ \\
\hline 62.5 & 0.7273 & 1.0715 & 1.1001 \\
\hline
\end{tabular}

\subsection{Effect of adsorbent particle size}

The effect of adsorbent particle size on bioadsorption of dyes is shown in Figure 3. The dyes adsorbed increased as the adsorbent particle size decreased. This fact is explainable as smaller particles have a large surface area than larger particles and hence adsorbe more dye during the initial stages of adsorption [19]. For this reason, adsorbent particle sizes of $125-250 \mu \mathrm{m}$ have been selected for all the batch experiements.

\subsection{Effect of carbon concentration}

The adsorption of the dyes on carbon was studied by varying the carbon concentration $(50-300 \mathrm{mg} / \mathrm{mL})$. The percentage of adsorption increased as the carbon concentration increased shown in Figure 4. This is attributed to increased carbon surface area and availability of more adsorption sites.

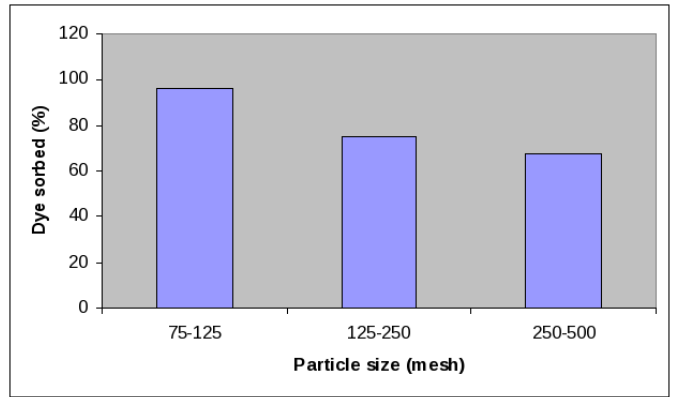

Figure 3: Effect of particle size on bioadsorption of MB by carbon of the epicarp of Ricinus communis (dye concentration: $10 \mathrm{mg} / 50 \mathrm{~mL}$; adsorbent dose: $100 \mathrm{mg} / 50 \mathrm{~mL}$; contact time: $2 \mathrm{~h}$; $\mathrm{pH}$ : 7.0)

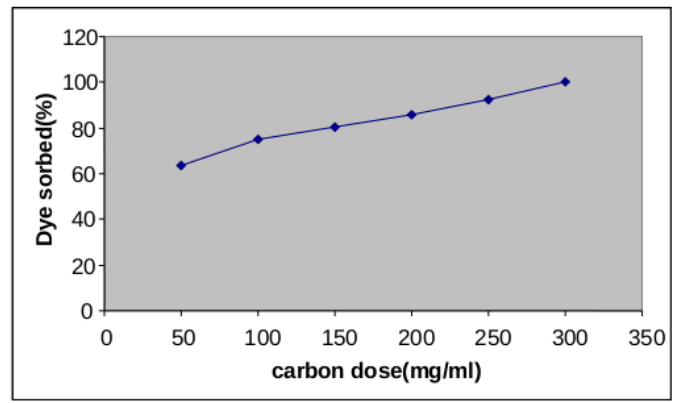

Figure 4: Effect of carbon dosage on bioadsorption of MB by carbon of the epicarp of Ricinus communis (dye concentration: 10mg/50mL; ; contact time: $2 \mathrm{~h}$; $\mathrm{pH}: 7.0$ )

\subsection{Desorption studies}

Desorption studies help to elucidate the nature of adsorption and recycling of the spent adsorbent and the dyes. The effect of $\mathrm{pH}$ on desorption of methylene blue is shown in Figure 5. When $\mathrm{pH}$ was varied from 2 to 9 , the percentage desorption was found to be decrease from 75.00 to 12.50 . Further increase in the $\mathrm{pH}$ of the solution did not show any significant increase in the percentage of desorption. From the results, it can be concluded that the adsorption mechanism was complex and dominated by both physisorption and chemisorptions.

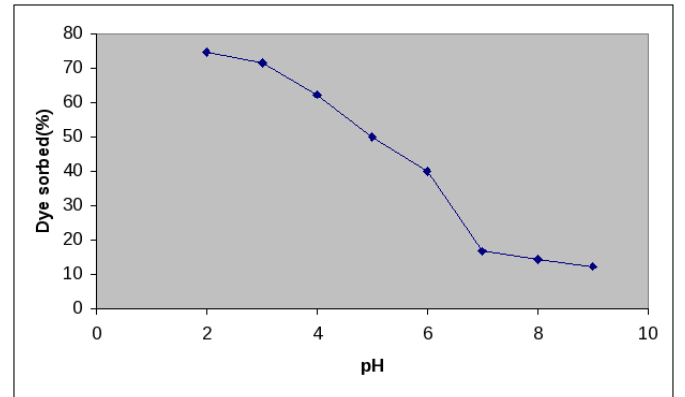

Figure 5: Effect of $\mathrm{pH}$ on desorption of $\mathrm{MB}$ by carbon of the epicarp of Ricinus communis (dye concentration: $10 \mathrm{mg} / 50 \mathrm{~mL}$; adsorbent dose: $100 \mathrm{mg} / 50 \mathrm{~mL}$; contact time: $2 \mathrm{~h}$ ) 


\subsection{Adsorption kinetics}

The bioadsorption kinetics of dyes is illustrated in Figure 6. The removal rates of dyes from solution were very rapid during the initial stages of the bioadsorption process. After a very rapid biosorption, dye uptake capacities increased with time and reached equilibrium values in approximately $2 \mathrm{~h}$. The three phases of dye adsorptions could be attributed to boundary layer sorption, intraparticle diffusion and sorption equilibrium, respectively.

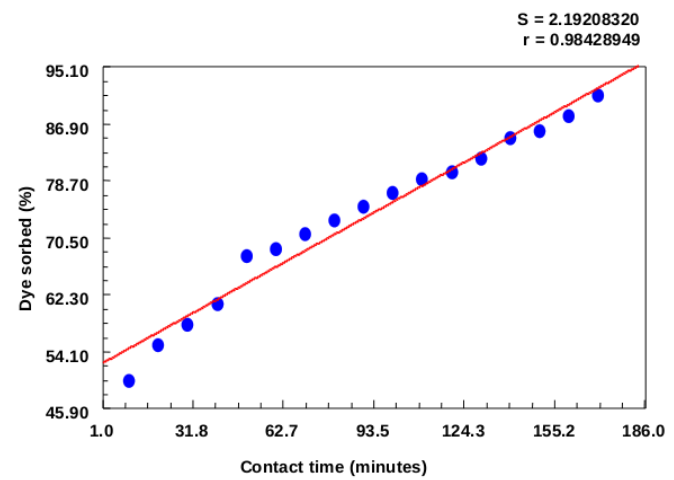

Figure 6: Bioadsorbtion kinetics of MB by carbon of the epicarp of Ricinus communis (dye concentration: $50 \mathrm{mg} / 50 \mathrm{~mL}$; adsorbent dose: $100 \mathrm{mg} / 50 \mathrm{~mL}$; particle size: $125-250 \mu \mathrm{m}: \mathrm{pH}$;7)

The kinetic data were treated with the following Lagergren's pseudo-first order rate equation:

$$
\log \left(q_{e}-q_{t}\right)=\log q_{e}-k_{\mathrm{ad}} t / 2.303
$$

where $q_{e}$ and $q_{t}(\mathrm{mg} / \mathrm{g})$ refer to the amount of dye sorbed at equilibrium and time $t(\mathrm{~min})$, respectively, and $k_{\mathrm{ad}}$ is the rate constant. The rate constant $k_{\mathrm{ad}}$ could be calculated from the slopes of the linear plots of $\log \left(q_{e}-q_{t}\right)$ verses $t$. The Lagergren plots of dye bioadsorption are shown in Figure 7. The high values of correlation coefficients showed that the data conformed well to the pseudo-first-order rate kinetic model.

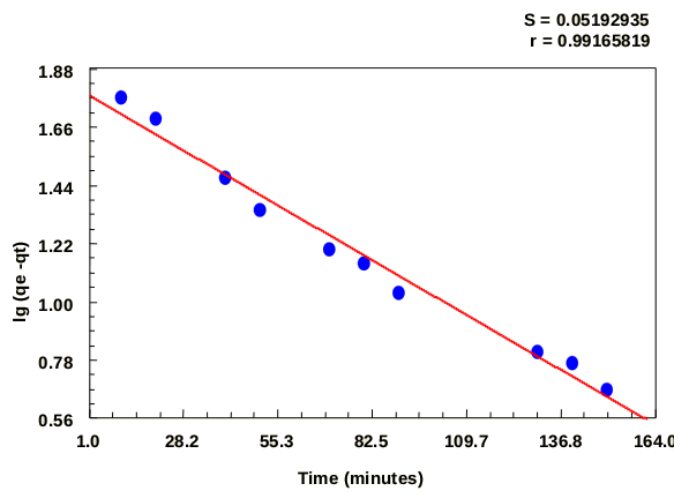

Figure 7: Lagergren plots for bioadsorbtion of MB by carbon of the epicarp of Ricinus communis

\subsection{Spectrochemical Characterization}

The surface morphology of the activated carbon was examined using scanning electron microscopy (SEM) at different magnification; the results are shown in Fig. 8. and Fig. 9. It was evident that the surface morphology of the activated carbon was different before and after adsorption.

\section{Conclusion}

This study confirmed that the bioadsorbent prepared from epicarp of Ricinus communis, a low cost agricultural waste, could effectively remove MB from an aqueous solution. The optimal $\mathrm{pH}$ for favorable adsorption of dye was 7 . The change of particle size had an effect on the bioadsorption of dye. The adsorption equilibrium was reached in approximately $2 \mathrm{~h}$. The isothermal data fitted the Langmuir and Freundlich model.So, the adsorbtion was physisorbtion. The bioadsorption processes followed the pseudo- firstorder rate kinetics.

\section{References}

[1] Gulnaz O, Kaya A, Matyar F and Arikan B, Sorption of basic dyes from aqueous solution by activated sludge, Journal of Hazardous Materials, 2004. 108(3):pp. 183 - 188. doi: 10.1016/j.jhazmat.2004.02.012

[2] Tsai WT, Chang CY, Lin MC, Chien SF, Sun HF and Hsieh $\mathrm{MF}$, Adsorption of acid dye onto activated carbons prepared from agricultural waste bagasse by ZnCl2 activation, Chemosphere, 2001. 45(1):pp. 51 - 58. doi:10.1016/ S0045-6535(01) 00016-9

[3] Santhy K and Selvapathy P, Removal of reactive dyes from wastewater by adsorption on coir pith activated carbon, Bioresource Technology, 2006. 97(11):pp. 1329 - 1336. doi : 10.1016/j.biortech.2005.05.016

[4] Brown P, Jefcoat IA, Parrish D, Gill S and Graham E, Evaluation of the adsorptive capacity of peanut hull pellets for heavy metals in solution, Advances in Environmental Research, 2000. 4(1):pp. 19 - 29. doi:10.1016/S1093-0191(00) 00004-6

[5] Singh K, Talat M and Hasan S, Removal of lead from aqueous solutions by agricultural waste maize bran, Bioresource Technology, 2006. 97(16):pp. 2124 - 2130. doi:10.1016/ j.biortech.2005.09.016

[6] Taty-Costodes VC, Fauduet H, Porte C and Delacroix A, Removal of $\mathrm{Cd}(\mathrm{II})$ and $\mathrm{Pb}(\mathrm{II})$ ions, from aqueous solutions, by adsorption onto sawdust of Pinus sylvestris, Journal of Hazardous Materials, 2003. 105(1-3):pp. 121 - 142. doi:10. 1016/j.jhazmat.2003.07.009

[7] Reddad Z, Gerente C, Andres Y and Le Cloirec P, Adsorption of Several Metal Ions onto a Low-Cost Biosorbent: Kinetic and Equilibrium Studies, Environmental Science \& Technology, 2002. 36(9):pp. 2067-2073. doi : 10.1021/es0102989

[8] Vijayaraghavan K, Palanivelu K and Velan M, Biosorption of copper(II) and cobalt(II) from aqueous solutions by crab shell particles, Bioresource Technology, 2006. 97(12):pp. 1411 1419. doi: 10.1016/j . biortech.2005.07.001

[9] Kweon DK, Choi JK, Kim EK and Lim ST, Adsorption of divalent metal ions by succinylated and oxidized corn starches, Carbohydrate Polymers, 2001. 46(2):pp. 171 - 177. doi: $10.1016 / \mathrm{S} 0144-8617(00) 00300-3$ 


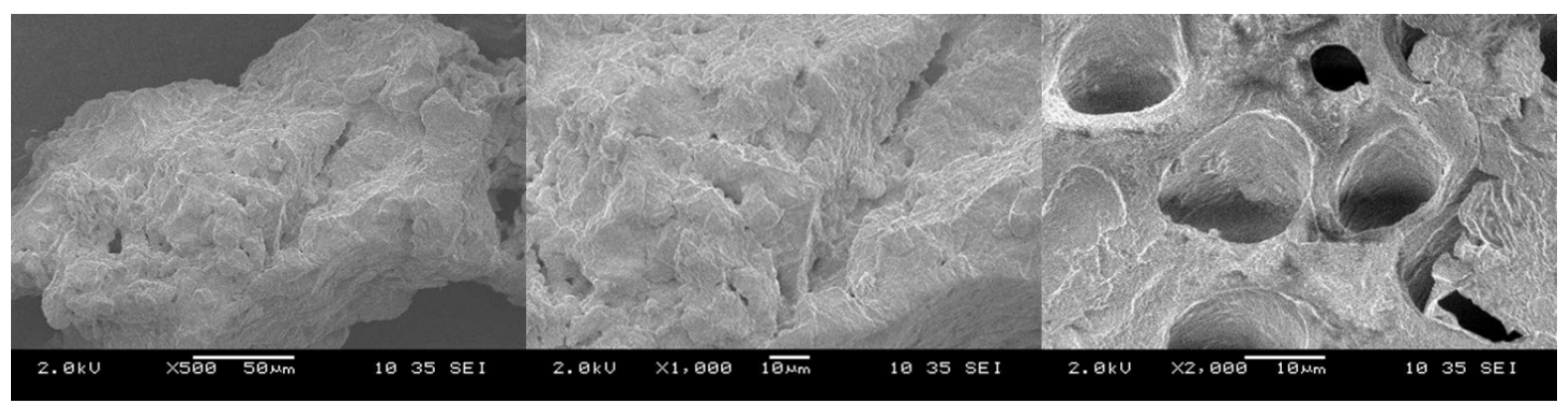

Figure 8: Cross section of activated carbon (Before adsorption)

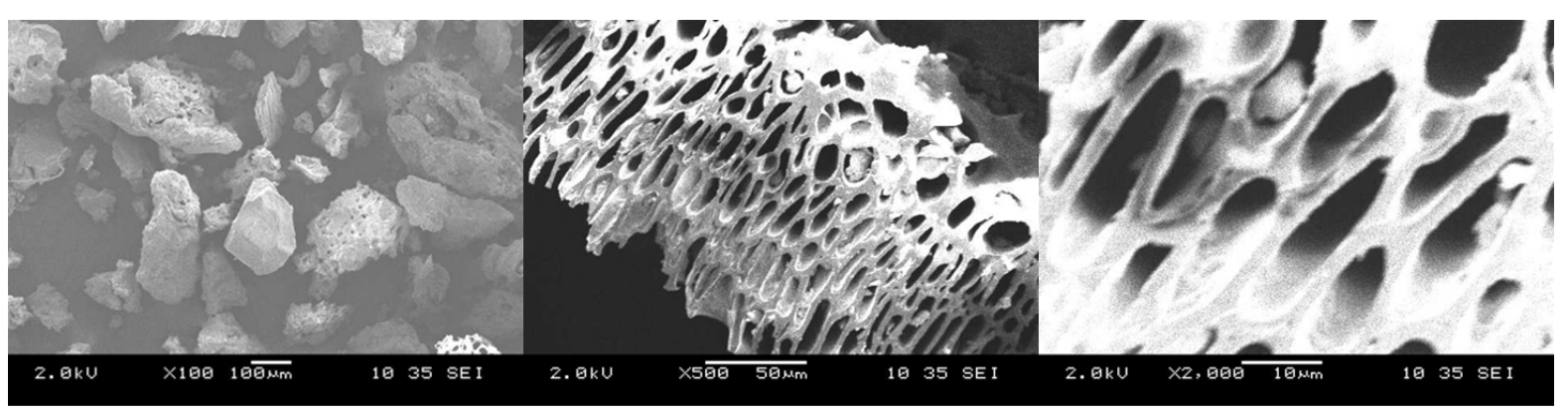

Figure 9: Cross section of activated carbon (After adsorption)

[10] Kumar U and Bandyopadhyay M, Sorption of cadmium from aqueous solution using pretreated rice husk, Bioresource Technology, 2006. 97(1):pp. 104 - 109. doi:10.1016/j. biortech.2005.02.027

[11] Ghimire KN, Inoue K, Miyajima T, Yoshizuka K and Shoji T, Adsorption of Some Metal Ions and Mineral Acids on Chitin, Chitin and Chitosan Research, 2001. 7(2):pp. 61-68

[12] Dhakal RP, Ghimire KN, Inoue K, Yano M and Makino K, Acidic polysaccharide gels for selective adsorption of lead (II) ion, Separation and Purification Technology, 2005. 42(3):pp. 219-225. doi:10.1016/j.seppur.2004.07.016

[13] Kumar KV, Optimum sorption isotherm by linear and nonlinear methods for malachite green onto lemon peel, Dyes and Pigments, 2007. 74(3):pp. 595 - 597. doi:10.1016/ j.dyepig. 2006.03 .026

[14] Gong R, Zhang X, Liu H, Sun Y and Liu B, Uptake of cationic dyes from aqueous solution by biosorption onto granular kohlrabi peel, Bioresource Technology, 2007. 98(6):pp. 1319 - 1323. doi : 10.1016/j.biortech. 2006.04.034

[15] Husseien M, Amer AA, El-Maghraby A and Taha NA, Utilization of Barley Straw as a Source of a Activated Carbon for Removal of Methylene Blue from Aqueous Solution, Journal of Applied Sciences Research, 2007. 3(11):pp. 1352-1358

[16] Pramanpol N and Nitayapat N, Adsorption of Reactive Dye by Eggshell and Its Membrane, The Kasetsart Journal, 2006. 40(SI):pp. 192-197

[17] Langmuir I, The Adsorption of Gases on Plane Surfaces of Glass, Mica and Platinum, Journal of the American Chemical Society, 1918. 40(9):pp. 1361-1403. doi:10.1021/ ja02242a004

[18] Teng H and Hsieh CT, Influence of Surface Characteristics on Liquid-Phase Adsorption of Phenol by Activated Carbons Prepared from Bituminous Coal, Industrial \& Engineering Chemistry Research, 1998. 37(9):pp. 3618-3624. doi:10.1021/ ie970796j

[19] McKay G, Otterburn M and Sweeney A, The removal of colour from effluent using various adsorbents. IV. Silica. Equilibria and column studies, Water Research, 1980. 14(1):pp. 21-27. doi : 10.1016/0043-1354(80)90038-X 